\title{
"VOCÊ É UMA MORENA MUITO BONITA": A TRAJETÓRIA TEXTUAL DE UM ELOGIO QUE FERE
}

\author{
"YOU'RE A BEAUTIFUL LIGHT BROWN-SKINNED WOMAN": \\ THE TEXTUAL TRAJECTORY OF A COMPLIMENT THAT HURTS
}

\author{
Glenda Cristina Valim de Melo*,** \\ Luiz Paulo da Moita Lopes***
}

\section{RESUMO}

Este artigo analisa a trajetória textual do elogio Vocêe uma morena bonita nos comentários de participantes de dois fóruns distintos. Além disso, visamos identificar que ordens de indexicalidade são mobilizadas na trajetória deste elogio específico. Para tal, este estudo se embasa nos pressupostos sobre raça das Teorias Queer, nos construtos teórico-analíticos sobre trajetória textual e ordem de indexicalidade propostos por Blommaert (2010; BLOMMAERT; DONG, 2008) e pistas indexicais por Wortham (2001). O instrumento etnográfico de geração de dados são os comentários postados no blog Blogueiras Negras e no site Pragmatismo Político. Os resultados indicam que o elogio percorre duas viagens distintas nos espaços citados e mobilizam três ordens de indexicalidade relacionadas à questão racial (o elogio é ofensa, o elogio/ofensa é aceitável, o elogio não é ofensa). As primeiras duas ordens de indexicalidade aparecem no Blogueiras Negras. Por outro lado, no Pragmatismo Político, além de as duas últimas serem encontradas, é possível perceber a ordem de indexicalidade na qual o elogio não é ofensa. Assim, tais ordens convocam Discursos igualmente tensionados na sociedade brasileira sobre o racismo.

Palavras-chaves: trajetória textual; ordem de indexicalidade; raça; teorias queer.

\section{ABSTRACT}

This article analyzes the textual trajectory of the compliment "Você é uma morena bonita" ("You're a beautiful light brown-skinned woman") presented in participants' commentaries

\footnotetext{
*. UNIRIO, Rio de Janeiro (RJ), Brasil, glendamelo09@gmail.com; UFRJ, Rio de Janeiro (RJ), Brasil. moitalopes@pq.cnpq.br

** Sou grata ao CNPq pela bolsa 159621/2010-0, no âmbito do Edital MEC/CAPES e MCT/CNPq/ FINEP No 28/2010 - Programa Nacional de Pós-Doutorado - PNPD 2010, que possibilitou este estudo. Tal bolsa foi concedida ao Projeto "Letramentos Digitais Singularidades do Ethos, Performances e Narrativas Identitárias", do Prof. Dr. Luiz Paulo da Moita Lopes (CNPq 560303/2010-06). Agradeço também ao meu supervisor Dr. Luiz Paulo da Moita Lopes por todo o processo de desconstrução e reinvenção para além dos muros acadêmicos.

***Agradeço ao $\mathrm{CNPq}$ pela Bolsa de Produtividade que propiciou esta pesquisa (CNPq 30331/2009-0), assim como ao auxílio à pesquisa da FAPERJ (E -26/110.065/2012) e ao PNPD (MEC/ CAPES e MCT/CNPq/FINEP) referido na nota anterior. Sou também grato ao CNPq pelo auxílio (470547/2012-0), concedido pelo Edital Universal (14-2012).
} 
in two different forums. Besides this, we intend to identify the indexicality orders mobilized in this specific compliment trajectory. The analytical framework is based on Queer Theory conceptualizations of race, on the theorethical-analytical constructs about textual trajectory and indexicality order proposed by Blommaert (2010; BLOMMAERT; DONG, 2008) and indexical cues by Wortham (2001). The data ethnographical instruments are commentaries posted on Blogueiras Negras' blog and Pragmatismo Político site. Results suggest that the compliment travels two distinct journeys in the spaces previously mentioned and mobilize three orders of indexicality related to race (the compliment is an offense, the compliment is acceptable, the compliment is not an offense). The two first orders can be observed on Blogueiras Negras. On the other hand, on Pragmatismo Político, besides the two orders, it is possible to perceive another: the compliment is not an offense. Thus, these orders call up the same Discourses in tension in Brazil about racism.

Keywords: textual trajectory; orders of indexicality; race; queer theories.

\section{INTRODUÇÃO}

Com a globalização, o desenvolvimento e o acesso às ferramentas computacionais cada dia mais inovadoras, a vida se torna mais fluida e fragmentada. As informações transitam por continentes na velocidade da fibra óptica enquanto os atores sociais, por redes sem fio, tentam se situar nesse contexto móvel, escorregadio e movediço que colabora na construção de vidas em fluxos e contingentes. Neste sentido, a mobilidade de pessoas, textos, Discursos ${ }^{1}$ e línguas está na ordem do dia. Em algumas horas podemos cruzar o Atlântico, e em poucos minutos, textos, Discursos e línguas percorrem trajetos inimagináveis no passado.

Assim, em tempos de fluidez (BAUMAN, 2008), as discussões e reflexões sobre a questão racial e seus efeitos semânticos chegam cada vez mais rápido às práticas sociais. Por mais que abordemos o tema raça e que Discursos sobre ela viajem pelo tempo e espaço, deparamo-nos ainda, em contexto brasileiro, com sedimentações e normalizações oriundas de ideologias do pensamento da ciência da raça e da democracia racial (SODRÉ, 1999; TELLES, 2003) sobre negras/os que geram(ram) muito sofrimento.

Esses tempos de reflexividade sobre nós mesmos têm sido também denominados Modernidade Recente (RAMPTON, 2006), nos quais uma série de teorizações sobre a vida social fazem críticas aos ideais modernistas sobre a ilegitimidade de certos sujeitos sociais os quais têm sido tradicionalmente

1 Segundo Gee (2004:15), discurso com letra minúscula está relacionado à linguagem em uso. Já Discurso, com letra maiúscula, indica formas de estar no mundo que "integram identidades ou modos combinados de 'dizer-fazer-pensar-sentir-valorar', [...] que nos tornam membros de um grupo", como, por exemplo, o Discurso dos linguistas aplicados. 
legitimados (BAUMAN; BRIGGS, 2003).Com base nesta crítica, esta investigação pretende analisar a trajetória textual do elogio Você é uma morena bonita, que se encontra no artigo de opinião Deixar de ser racista, meu amor, não é comer uma mulata!, de Charô, no blog Blogueiras Negras, presente nos comentários de participantes em dois fóruns distintos. Além disso, visamos identificar que ordens de indexicalidade são mobilizadas na trajetória textual desse elogio específico, na tentativa de compreender seus efeitos semânticos.

De acordo com Gomes (2010), podemos dizer que a questão racial no Brasil tem sido deixada à sombra, apesar do seu crescente destaque na produção científica brasileira das Ciências Sociais e Humanas, devido à inserção de negras/ os nas universidades que almejam compreender as relações raciais no contexto das desigualdades sociorraciais. Para a autora, tal questão não significa apenas uma mudança no olhar da ciência, mas também uma pressão de movimentos sociais de caráter identitário e de sujeitos sociais deixados à margem durante a Modernidade. Neste sentido, os estudos que trazem à visibilidade negras/os podem colaborar para desestabilizar as sedimentações de raça que indexicalizam Discursos que transitam pela sociedade e percorrem espaços outrora impensáveis.

Compartilhando da proposta de Gomes (2010), neste estudo escolhemos o elogio mencionado devido à relevância do tema para a comunidade negra, especificamente para as mulheres negras que, segundo o $\mathrm{IBGE}^{2}$, constituem as camadas mais desfavorecidas em vários quesitos. São construídas como exóticas e erotizadas, e sua humanidade é menos validada que as outras (BUTLER, 2004). Além disso, buscamos ampliar a discussão sobre linguagem e raça no campo dos estudos linguísticos aplicados, nos quais as publicações sobre tal questão são escassas exceto por algumas pesquisas: Moita Lopes, 2002; Costa de Paula, 2003, 2010; Ferreira, 2006, 2009; Melo; Moita Lopes, 2013, 2014a e2014b.

Para tal, este artigo primeiramente aborda a questão racial pelas perspectivas das Teorias Queer; em seguida, introduz os construtos teórico-analíticos, para então apresentar o contexto e a metodologia de pesquisa e, finalmente, passar à análise.

\section{TEORIAS QUEER E RAÇA: ALGUMAS CONSIDERAÇÕES}

Neste estudo, ancoramo-nos nas perspectivas das Teorias Queer ${ }^{3}$, que compreendem raça como uma construção socio-histórica, discursiva e performativa,

\footnotetext{
2 Ver mais informações sobre a questão em < http://www.ibge.gov.br/censo2010/>

3 Os princípios teóricos das Teorias Queer são abordados,por exemplo, em Sedgwick ([1990] 2008), Sullivan (2003), Barnard (2004), Louro (2004) e Melo; Moita Lopes (2013).
} 
como propõem Melo; Moita Lopes (2013, 2014a,2014b), embasados na perspectiva de gênero sugerida por Butler ([1999] 2003, 2004). Compartilhamos também da reflexão de Muñoz (1999), Sommerville (2000), Sullivan (2003) e Barnard (2004) de que a raça, assim como gênero e linguagem, também é performativa, como veremos ao longo do artigo. Assim, ao estudarmos a questão racial, devemos também considerar o gênero, a sexualidade, a classe social etc., pois, conforme os autores citados, é possível entender os sujeitos sociais de uma forma mais complexa, ou seja, para além da raça, da sexualidade, do gênero, da classe social etc.

Sendo assim, antes de passarmos à reflexão sobre a questão racial como performativa, primeiramente precisamos compreender a concepção dos atos de fala como performativos de Austin e de Derrida. O termo performativo é oriundo das reflexões de Austin ([1962]1990) sobre como usamos a linguagem para fazer coisas na vida social. De acordo com o autor, para além dos atos considerados constatativos (verdadeiros ou falsos) haveria os performativos (vistos como bem ou mal sucedidos). Segundo ele, ao serem proferidos os atos de fala performativos, atendendo às circunstâncias contextuais e textuais, produziriam o que descrevem. Em outras palavras, ao enunciarmos uma ação, ela é realizada pela linguagem, ou seja, é performativa. $\mathrm{O}$ autor exemplifica este ponto ao apresentar o ato performativo de batizar alguém, isto é, ao enunciar eu te batizo o padre exerce a ação (um agir) de batizar alguém. Neste particular, somente o padre estaria legitimado a batizar, o que tornaria nulo este mesmo enunciado se fosse proferido por qualquer outra pessoa. Posteriormente, Austin ([1962]1990) desconstrói esta dicotomia entre performativo/constatativo ao considerar todos os atos de fala como performativos, excluindo, contudo, a estiolação, ou seja, o uso da linguagem no palco, na ficção etc.

Na releitura dos atos de fala de Austin, Derrida ([1972]1988) indica que não seriam necessárias condições específicas para que um ato de fala fosse considerado performativo. Para este autor, os atos de fala performativos também incluem aqueles que, na perspectiva austiniana, não atenderiam às circunstâncias contextuais e textuais - ou à prerrogativa da felicidade (AUSTIN, [1962]1990): as estiolações. Em outras palavras, de acordo com Derrida, a linguagem é performativa e como tal todos os atos de fala são também performativos. Ainda segundo o estudioso, o performativo é naturalizado pela iterabilidade e pela citacionalidade, ou seja, por meio da repetição de tais atos de fala nas práticas sociais e de sua propagação pelas diversas instituições como a mídia, a escola, a igreja etc. Nesta perspectiva, a linguagem, então, é entendida como ação e constitui os corpos nas práticas sociais, ou seja, o discurso é primordial na (re)invenção de nós mesmos e dos outros. Considerando Pennycook (2007), compreendemos que pela linguagem, enquanto 
ação no mundo (performance), agimos nas práticas sociais e nos (re)inventamos; ou, nas palavras de Butler (1997, p. 8), "nós fazemos coisas com a linguagem, produzimos efeitos pela linguagem e nós fazemos coisas para a linguagem, mas a linguagem é também a coisa que fazemos".

As concepções de performativo e de linguagem mencionadas, assim como a teorização sobre gênero sugerida por Butler ([1999]2003, 2004), levam à compreensão de raça, nesta investigação, como uma construção social, discursiva, performativa e histórica (SULLIVAN, 2003) que resulta dos efeitos semânticos de Discursos sobre raça propagados na sociedade. Nestes Discursos, em contexto brasileiro especificamente, incluem-se os da Escravidão, Ciência da Raça, Democracia Racial, Negritude (MUNANGA, 1986; SODRÉ, 1999, TELLES, 2003) e também aqueles de Mestiçagem (MUNANGA, 2010, p. 445), este último simbolizando a etnia brasileira "capaz de acolher a gente variada que ao país se juntou".

Como Butler ([1998] 2002), não negamos a existência da materialidade ou, nas palavras de Pinto $(2007$, p. 3$)$, a anatomia; entretanto, buscamos desconstruir "[...] os atos de fala que se organizam em torno dela". Preocupam-nos, dessa forma, os atos de fala performativos que qualificam atores sociais única e exclusivamente com base em tais Discursos. Questionamos - assim como a autora - os efeitos semânticos dos Discursos que se pautam apenas nesta materialidade corpórea para construir os sujeitos sociais, trazendo, desta forma, violência aos corpos abjetos como os dos negros, dos gays, das lésbicas, das mulheres e dos indígenas, por exemplo.

Segundo Butler (2004, p. 2), "os humanos são compreendidos diferentemente dependendo de sua raça, da legitimidade desta raça, sua morfologia e o reconhecimento dessa morfologia...". Se considerarmos, por exemplo, a escravidão, veremos que os corpos negros eram construídos como inferiores aos corpos não negros; já na chamada democracia racial, a construção discursiva se constituía de atos de fala performativos de igualdade entre os atores sociais de todas as raças. Embasados em Foucault (2010), ao tratar dos anormais, podemos dizer que aquele que menciona o racismo seria considerado o anormal, visto que, nos Discursos sobre a democracia racial, permeiam valores do senso comum de que o ator social que aborda a questão racial é compreendido como racista, problemático e/ou portador de alguma patologia psicológica. Por outro lado, na atualidade, tendo em vista os movimentos sociais, negras/os são também perpassados por Discursos de negritude ou atos de fala performativos de valorização de corpos ébanos. Isso nos mostraria, como cita Sullivan (2003), que a construção discursiva e performativa depende do momento sócio-histórico em que nos situamos. 
De acordo com Heilborn (2006, p. 46), "a forma como cada cultura considera adequado o uso dos corpos diz respeito às ideias dominantes na sociedade, em cada momento histórico". Assim, conforme Giacomini (2013), no período escravocrata os corpos das mulheres negras eram mercadorias do senhor que poderia usá-los e violentá-los de acordo com sua vontade. Já no momento atual, deparamo-nos nas mídias digitais, por exemplo, com construções corpóreas que valorizam o cabelo crespo de negras/os.

Em outras palavras, os atos de fala performativos sobre os atores sociais ébanos, brancos, amarelos e outros viajam pelas mídias de cada época; são repetidos, propagados, compartilhados e marcam os corpos. Se considerarmos as raças branca, amarela, negra etc. na sociedade ocidental, deparamo-nos com textos viajantes que há séculos propagam a superioridade da primeira sobre todas as outras. Um exemplo disso estaria nos estudos da Ciência da Raça e também de Eugenia que propõem, por meio de pesquisas científicas, a superioridade dos corpos brancos pelas características físicas e/ou psicológicas que lhes são atribuídas. Os sistemas de classificação de raça de Philippe Rushton e de Charles Linnaeus ${ }^{4}$ (SULLIVAN, 2003) exemplificam esta questão. Com base em estudos científicos como os citados, alguns países como Alemanha, Estados Unidos, Suécia e Suíça transformaram em abjetos atores "indesejáveis" (MACIEL, 1999) tais como os judeus. No Brasil, tal aspecto pode ser percebido, por exemplo, nos Discursos de Eugenia, que segundo Maciel (1999) compreendiam a miscigenação como forma de limpar o país de corpos abjetos (negros e indígenas).

Vale também mencionar o patrulhamento da raça, assim como o do gênero (BUTLER, 2004). Os Discursos relacionados ao patrulhamento da raça seriam precipitados quando negras/os ocupam lugares tradicionalmente não destinados a eles/as, como por exemplo, a administração de uma grande empresa, a entrada em algumas lojas etc. Ao adentrarem espaços que não seriam seus, o sistema que funciona por meio de recursos semióticos múltiplos entraria em vigor para colocar esses corpos abjetos em seus devidos lugares, por meio de performances corpóreas discursivas bem delimitadas. No Brasil, este sistema naturalizado parece velado em algumas circunstâncias, mas, se analisado detalhadamente, torna-se explícito em muitas situações.

Considerando a trajetória textual de atos de fala performativos sobre raça, aqueles sobre a democracia racial continuam a viajar pelas mídias e são entextualizados por diversos atores sociais. Um exemplo seria a discussão sobre as

\footnotetext{
$4 \mathrm{O}$ sistema de Philippe Rushton propõe três raças: a oriental, a branca e a negra, todas elas classificadas também pelo biológico (tamanho do cérebro e do pênis) e pelo psicológico. Já no de Charles Linnaeus, somos divididos em vermelhos, brancos, amarelos e negros.
} 
cotas. Nos discursos contrários, pode-se observar a viagem de textos de democracia racial. Tais atos de fala performativos, especificamente, apagam em seu percurso os problemas raciais e perpetuam a ilusão de que vivemos todos sob as mesmas oportunidades, mascarando assim o racismo e as desigualdades que nos assolam. Apesar da relevância quantitativa de Discursos sobre a negritude, no senso comum ainda observamos hoje a influência do ato de fala performativo da democracia racial do início do século XX. Portanto, mesmo com a disseminação de atos de fala performativos de valorização da raça negra, deparamo-nos com elogios como você é uma morena bonita quando as pessoas querem se referir às chamadas mulheres negras belas.

Compreendemos, embasados em Muñoz (1999), que é preciso desidentificar os sujeitos sociais negros de Discursos que inferiorizem esta materialidade específica, reinventando-a e incluindo negras/os em todos os contextos. Para tal, torna-se necessário reinventar Discursos outros e performances identitárias outras para tais atores sociais. Por outro lado, é essencial desidentificar o traço performativo branco como não sendo uma raça, ou seja, uma categoria dada e já padronizada, e questionar os efeitos semânticos destas construções raciais brancas nos corpos (ver MOITA LOPES, 2013).

Todas as cristalizações de sentidos citadas nesta seção trazem sofrimento aos corpos negros, pré-determinando seus lugares e suas performances e aprisionandoos às novas senzalas veladas que machucam e ferem. Neste sentido, concordamos com Butler ([1998] 2002, 2003, 2004) sobre a necessidade de desestabilizar/ queerizar estas normas que sedimentam Discursos e marcam a materialidade, antes da existência do sujeito. Em tempos de Modernidade Recente, na qual há uma crítica ao pensamento modernista, observamos a necessidade de reflexão sobre tais Discursos e os seus efeitos nos corpos. Parece-nos viável considerar que, assim como cita Sedgwick ([1990] 2008, p.35), da mesma forma em que "há muitas dimensões da sexualidade", existem também muitas dimensões de raça, interseccionadas e entrecruzadas com gênero, classe social, nível de escolaridade, sexualidade etc. À medida que os textos sobre a temática racial viajam translocalmente, muitas outras dimensões podem ser reinventadas e entextualizadas.

\section{INSTRUMENTAL TEÓRICO-ANALÍTICO}

A globalização promoveu um acesso maior às Tecnologias de Informação e Comunicação, sendo as redes sociais e mídias digitais frutos desse acesso. Além de 
ser um espaço convergente de vários atores sociais e Discursos (MELO; MOITA LOPES, 2014b), a internet, parafraseando as palavras de Milton Santos (2000) sobre o mundo globalizado, é também um lugar onde tudo passa pelo discurso. Neste contexto discursivo, movediço e arenoso, deparamo-nos com a mobilidade de pessoas, o que resultaria na mobilidade de recursos (socio)linguísticos (BLOMMAERT;DONG, 2007). Segundo os autores, da possibilidade de contato eletrônico - e acrescentamos, com os percursos imprevisíveis que os textos percorrem na atualidade - podem emergir novas formas de inovação da linguagem e de prestígio linguístico. Com base em tais estudiosos, é possível dizer que os repertórios linguísticos são menos previsíveis e significativamente mais complexos. Desse modo, se de um lado a linguagem ou tais repertórios ancoram os sujeitos sociais a contextos locais e/ou específicos, por outro lado eles também nos conectam aos contextos translocais. Ademais, a linguagem ainda se move juntamente com os atores pelo tempo e espaço, transformando-se também em uma ferramenta para a mobilidade (BLOMMAERT; DONG, 2007:19).

Com foco nesta mobilidade, introduzimos aqui o construto de trajetória textual, ou seja, que se refere a como entextualizações de textos percorrem o tempo e o espaço ao clique do mouse ou ao toque da tela. Embasados em Blommaert (2008, 2010), compreendemos que tais textos e Discursos circulam e viajam velozmente pela rede, carregando suas características históricas, agregando novos sentidos e promovendo a socialização de pessoas por meio de vários recursos semióticos. Nas palavras de Maryns; Blommaert (2013: 2), "as histórias de sujeitos se tornam um input de sequências de diferentes entextualizações $[\ldots]^{\prime \prime}$.

Considerando o artigo de opinião produzido por Charô Nunes, intitulado "Deixar de ser racista, meu amor, não é comer uma mulata!", cujas trajetórias textuais são foco desta investigação, sua viagem se inicia pelo espaço online Blogueiras Negras; segue pelo Facebook do mesmo blog, percorre o grupo fechado das mesmas blogueiras na rede social citada, e também o Twitter. Além disso, em uma rápida busca pela internet, tivemos acesso a outros roteiros seguidos pelo mesmo texto, incluindo um site sobre política que estudaremos aqui, blogs variados destinados às mulheres, a causas raciais etc. Desta forma, os Discursos mobilizados por esse texto são apropriados por sujeitos sociais diversos (conhecidos ou anônimos e de localidades distintas). Tais atores cortam, colam, copiam e se apropriam das práticas linguageiras de outros para construir seus textos e convocar certos Discursos. Conforme Maryns; Blommaert (2013: 2) apontam, esse percurso textual envolve "reformulações, renomeações e reenquadres da história original". Tais renomeações e mudanças podem ser observadas, por exemplo, na entextualização do artigo de 
Charô no site político : algumas imagens do texto foram alteradas e o título se tornou 'Comer uma mulata' não lhe fará menos racista. A entextualização é aspecto importante na trajetória textual, visto que é por meio dela que os textos viajam e percorrem infinitos percursos. Aqui, compreendida na perspectiva de Bauman, Briggs (1990), ela é a capacidade reflexiva do discurso de ser compartilhado em diferentes sistemas de significação e o enquadramento do texto que carrega suas marcas para outros espaços.

Retomando o artigo de opinião, foco desta pesquisa, e observando sua entextualização nos comentários dos participantes, podemos dizer que ele ganhou outros pertencimentos e sentidos que são recontextualizados por cada participante. Sendo assim, segundo Fabrício (2013, p. 156), os textos percorrem múltiplos trajetos, cuja versatilidade de roteiros nos encaminha para "intercâmbios, trocas, reavaliações e transformações de textos 'em trânsito' por contextos diferentes". Compreendemos, então, que em cada percurso há um novo texto, múltiplas entextualizações são possíveis e novos valores são precipitados por sujeitos sociais, cujos repertórios diversos dependerão de suas histórias de vida. Assim, ainda conforme Fabrício, "esses contatos produzem uma pluralidade de significados articulados em textos e discursos que, dispersos em sua profusão, não os dão a conhecer" (2013, p. 145).

Outro aspecto relevante a mencionar é que, nesta viagem de textos, a indexicalidade é central (BLOMMAERT, 2006), pois tais textos, pelos índices linguísticos (SILVERSTEIN, 2003), também apontam para valores que permeiam a sociedade, ou seja, precipitam sentidos do contexto translocal nos Discursos locais. É por meio do fenômeno da indexicalidade (OCHS, 1992; BLOMMAERT, 2006, 2010; ROCHA, 2013), que os valores, as normas, os Discursos e as ideologias são impulsionados em uma perspectiva translocal, mostrando-nos, assim, que sentidos do mundo impessoal podem ser mobilizados em nível pessoal ou em escala local por atores variados. Assim, os textos deixam de pertencer a territórios e passam por contextos para além do local e da história de sua primeira versão via recursos semióticos múltiplos ou por meio de índices linguísticos.

De acordo com Blommaert (2010), a indexicalidade é ordenada em duas ordens: a indexical e a de indexicalidade. A primeira se refere a um construto que nos possibilita analisar como os sujeitos sociais, em suas performances identitárias, indexicalizam Discursos das grandes narrativas que orientam suas vidas sociais (SILVERSTEIN, 2003). Já a segunda, embasada no viés foucaultiano

5 Para visualizar essa entextualização, acessar: http://www.pragmatismopolitico.com.br/2013/08/ deixar-de-ser-racista-nao-e-comer-uma-mulata.html? trashed $=1$ \&ids $=74350$. 
de ordem do discurso - compreendida, segundo Blommaert (2006, 2010), como procedimentos impostos ou por qualquer sociedade ou pelo próprio discurso que controlam as produções discursivas, ora fazendo emergir alguns discursos, ora outros, relacionando-se aos valores normatizados, hierarquizados, estratificados e apontados no processo de indexicalização de Discursos (BLOMMAERT, 2010).

Conforme esse autor, tais ordens de indexicalidade são estratificadas e hierarquizadas, indicando, assim, a relação de poder nelas existente. Desse modo, Blommaert (2010) faz uso do termo escala, emprestado da Geografia e da História, para indicar "o movimento de mensagens ou pessoas no espaço e pelo tempo que são constituídos por normas, expectativas e códigos" (32). Para ele, ao enunciarmos em escala pessoal (local) estamos também mobilizando valores, ideologias em escala impessoal (translocal). Tais fenômenos discursivos e sociais são indissociáveis do tempo e do espaço. Segundo Melo; Moita Lopes (2014b), embasados em Blommaert (2010), "escalas diferenciadas apontam para níveis distintos de normalizações entre os sentidos (de/co)notacionais".

Assim, ao produzir seu artigo de opinião e citar cinco elogios que ofendem mulheres negras, Charô mobiliza ideologias, valores que estão estratificados e hierarquizados em seu texto por meio de ordens de indexicalidade. $\mathrm{O}$ mesmo ocorre na trajetória textual desse artigo, ao ser entextualizado em outros espaços online ou em comentários, destinados a outros públicos diferentes daqueles do primeiro percurso. Neles, são precipitadas outras ordens de indexicalidade, e a cada entextualização novos sentidos são construídos, como veremos ao longo da análise.

Para a análise das trajetórias textuais referentes ao elogio "Você é uma morena bonita", dos processos de entextualização e das ordens de indexicalidade, construtos teórico-analíticos discutidos anteriormente, embasamo-nos, entre outros, nas pistas indexicais de Wortham (2001) observáveis nos comentários. Apesar de tais pistas serem usadas pelo estudioso para sinalizar posicionamentos interacionais, aqui são elas empregadas para nos indicarem os Discursos e os valores movimentados nos comentários analisados, permitindo-nos compreender as ordens de indexicalidade hierarquizados. Entre as pistas indexicais, sugeridas por Wortham (2001), utilizaremos: referência (os elementos do mundo ao qual o narrador se refere); predicação (a caracterização de elementos mencionados pelo narrador); citação $^{6}$ (relacionada à citação da fala do outro para recriar um momento da interação) ${ }_{i}$ índices avaliativos (itens lexicais, construções gramaticais, sotaque etc. que caracterizam socialmente grupos sociais ou sujeitos sociais); modalidade epistêmica (quando o narrador se posiciona em relação ao que está sendo dito) e

6 Entextualização na perspectiva de Bauman; Briggs (1990). 
descritores metapragmáticos (verbos 'de dizer' usados pelo narrador para se referir ou predicar o que é contado na história).

\section{METODOLOGIA E CONTEXTO DE PESQUISA}

Esta pesquisa se caracteriza como de caráter etnográfico virtual nas perspectivas de Hine (2000, 2005), Guimarães Jr (2005), Rutter; Smith (2005). Como tal, buscamos na internet blogs sobre mulheres negras em contexto brasileiro. Dentre os encontrados, o Blogueiras Negras ${ }^{7}$, destinado às mulheres negras e feministas, que aborda assuntos voltados para a temática da negritude e do feminismo, chamou-nos atenção pela qualidade dos textos, nível escolar das participantes, grau de militância e qualidade de organização do espaço.

$\mathrm{Na}$ exploração desse blog, um dos trajetos do elogio, constatamos que havia uma página e um grupo fechado sobre ele no Facebook. A página foi curtida por um dos pesquisadores, que iniciou sua participação no grupo. Somente após alguns meses notamos serem necessários autorização, $\log$ in e senha para acesso aos comentários das/os participantes no Blogueiras Negras. Todo o processo etnográfico se iniciou no mês de julho de 2013, estendendo-se até janeiro de 2014, incluindo alguns comentários de um dos pesquisadores no grupo fechado e a curtida de textos no Facebook.

O blog reúne vários textos relevantes à comunidade negra feminina e discute temas diversos como racismo, sexualidade etc. O lugar se configura como importante espaço de troca de experiências vivenciadas por várias mulheres brasileiras e também por homens que apreciam a temática. As vozes dessas mulheres, outrora apagadas na Modernidade, são ouvidas por outras mulheres cujos relatos geram comentários múltiplos. Vale dizer que existe uma dinâmica interessante na publicação de textos. Há uma agenda no grupo fechado do Facebook que é preenchida com os nomes das mulheres que produzirão um artigo no Blogueiras Negras; sendo assim, diariamente há publicações novas, processo que pode ser caracterizado como uma prática social intensa de letramento (MOITA LOPES, 2005).

Após leitura de diversos textos, optamos pelo artigo de opinião Deixar de ser racista, meu amor, não é comer uma mulata!, publicado em 29 de maio de 2013 por Charô Nunes, uma das organizadoras do blog. Esse artigo compõe-se

\footnotetext{
7 A autora do texto e uma das coordenadoras do blog autorizou nossa pesquisa e solicitou que seu nome e o do blog fossem mantidos no original. Mais informações do blog no site http://blogueirasnegras. org/.
} 
de cinco imagens de mulheres negras diferentes, cada uma ilustrando um elogio, e foi selecionado porque a autora questiona os efeitos de atos de fala performativos, que - mascarados por elogios - ferem mulheres negras. Nesse espaço, encontramos 234 comentários de sujeitos sociais diversos e deste total, em torno de 35 foram publicados por homens de diferentes raças e localidades, incluindo um estrangeiro. Os comentários, que se iniciam em 29 de maio e seguem até 5 de dezembro de 2013, são postados em horários variados. A maioria deles é enviada por mulheres que se compreendem como negras, mas há também posts de mulheres de outras raças. Ao final do seu texto, Charô convoca os leitores a citarem outros elogios, apresentarem questões sobre o racismo com base em suas experiências e comentarem o seu texto. Uma grande parte dos comentários segue, então, as instruções da autora.

Já no outro trajeto analisado, Pragmatismo Político ${ }^{8}$, o texto de Charô, Comer uma Mulata não lhe Fará Menos Racista, foi publicado no dia 28 de agosto do mesmo ano, às $12 \mathrm{~h} 20 \mathrm{~min}$. $\mathrm{O}$ objetivo deste espaço é discutir de forma crítica múltiplos temas como política, educação, cultura etc. A opção também por esse blog ocorreu devido aos temas serem voltados para um público mais eclético e direcionado para aqueles que compreendem, de acordo com o site, que tudo passa pela educação ideológica e política. Aqui, percebemos nos comentários uma participação maciça de homens de raças diversas, parecendo predominar a branca. Foram encontrados 158 comentários que começaram a ser postados em 23 de agosto de 2013 e terminam em 27 de dezembro do mesmo ano. Verificamos que poucas mulheres, neste site, comentam o texto de Charô e que alguns participantes seguem à risca as instruções apresentadas pela autora, visto que a discussão se centra na (in) existência do racismo. Nesse percurso, observamos que o título do artigo foi modificado e algumas fotos também, sinalizando, assim, de acordo com Maryns; Blommaert (2013), que o roteiro textual envolve alterações e mudanças da história original.

$\mathrm{O}$ artigo de Charô em questão apresenta cinco elogios racistas comumente ditos às mulheres negras na sociedade brasileira. São eles: "Você é uma morena muito bonita"; "Seu cabelo é muito bonito, posso pegar?"; "Você tem traços delicados", "Você tem a bunda linda"; "Você é uma mulata tipo exportação." A autora analisa - e critica - cada um desses elogios; ao final, enfatiza a questão das mulatas tipo exportação e pede a opinião das blogueiras sobre sua produção textual e/ou outros elogios que porventura não tenham sido mencionados. Para esta investigação, centramo-nos especificamente na trajetória textual de um elogio: "Você é uma

8 Apesar de ser um site público, para preservar os participantes da investigação, alteramos seus. Salientamos ainda que não colocaremos 2013 após os nomes, visto que todos os dados foram gerados em tal ano. 
morena muito bonita." Nossa escolha é orientada pelo chamado fenômeno do embranquecimento observado no senso comum em contexto off/online e também pela dicotomia entre negra versus morena construída pela autora. Salientamos que o instrumento etnográfico de geração de dados foram os 392 comentários acima citados, incluindo os comentários curtidos por um dos autores deste artigo.

\section{AS TRAJETÓRIAS TEXTUAIS DO ELOGIO: "VOCÊ É UMA MORENA MUITO BONITA"}

Observando a trajetória do texto de Charô nos comentários das/os participantes do Blogueiras Negras, podemos dizer que ele foi entextualizado em atos performativos diferentes, tais como: elogiar o texto de forma geral, tecer opiniões sobre apenas um, alguns ou todos os elogios citados, discordar total ou parcialmente da autora e acrescentar elogios. Salientamos que apesar do artigo percorrer outras viagens, como grupo fechado no Facebook e Twitter, a autorização para esta investigação se refere apenas aos comentários presentes no blog Blogueiras Negras. Já no percurso do mesmo artigo nos comentários do Pragmatismo Político, percebemos que, uma parte da entextualizações compreende o elogio como ofensa aos corpos das mulheres ébanos ea maioria aceita o elogio.

Contudo, identificamos outra ordem de indexicalidade específica e predominante no Pragmatismo Político: o elogio como não ofensa. Ademais, observamos que há ainda roteiros discutidos com mais ênfase em cada espaço, como por exemplo, entextualizações que discutem o termo negro no Blogueiras Negras. Vimos ainda que nas entextualizações do Blogueiras Negras, há uma sedimentação da dicotomia morena versus negra ou vice-versa. Enquanto que nas entextualizações do Pragmatismo Político, percebemos a dicotomia existência versus inexistência do racismo.

A seguir, apresentamos as duas trajetórias textuais, no Blogueiras Negras e no Pragmatismo Político, e as ordens de indexicalidade mobilizadas pelos participantes nos percursos estudados.

\section{TRAJETÓRIA TEXTUAL DE VOCÊ É UMA MORENA MUITO BONITA NO BLOGUEIRAS NEGRAS}

Nesta trajetória textual, observamos duas ordens de indexicalidade distintas ao longo dos comentários: os elogios são ofensas e a aceitação do elogio. A primeira 
delas ratifica o Discurso de Charô de que o elogio Você é uma morena bonita é ofensivo e racista. As participantes do Blogueiras Negras, que discutem muito este ponto, entextualizam o elogio, concordando com a proposta da autora. Esta posição é apresentada por Adelina, por exemplo, que sintetiza uma boa parte dos comentários analisados. Ela qualifica negativamente tais elogios pela predicação (elogios degradantes); além disso, aborda o fato de ser chamada de morena como algo rotineiro em seu cotidiano, observado pela predicação (morena) e pela referência temporal e local(diariamente no meu trabalho), que sinalizam a frequência e local onde tal ato de fala performativo é enunciado:

\footnotetext{
Sou chamada de morena diariamente no meu trabalho e como não tenho papas na língua, advirto a pessoa: "Morena não, por favor, sou NEGRA." E a resposta que mais escuto é: "Não, vc nem é tão negra assim, é melhor ser chamada de morena." Affff... a ignorância que perpetua na cabeça das pessoas encobre a falta de informação, um racismo "as avessas" e a discriminação escondida em "elogios degradantes" à nós, mulheres negras. Adorei o artigo e fiz questão que postá-lo no face. Parabéns!!! (Adelina).
}

Adelina ainda faz uso de citação ("Não, vc nem é tão negra assim, é melhor ser chamada de morena"), sugerindo que outros não a constroem como negra e sim a embranquecem. Além disso, a predicação (tão negra assim, é melhor) indica uma desvalorização da mulher negra e uma valorização da morena. A participante, em ação contrária a das vozes que traz, critica o elogio, indicado pela predicação (morena) e pela referência adverbial de negação (não), e se reafirma negra, como apontado pela predicação (por favor, sou NEGRA) e pela letra maiúscula, o que sugere grito nas redes sociais. Verifica-se também o emprego do símbolo Afff acompanhado de reticências, um índice avaliativo utilizado com frequência nas redes sociais, que indexicalizam irritação por parte de Adelina quanto ao racismo.

Cabe salientar também que as aspas e a citação de seu próprio Discurso podem indicar que tal ato de fala performativo fora enunciado em outras interações, dando veracidade ao seu relato. Ressaltamos também que, além de blogs e sites que entextualizam o artigo de Charô, há outros roteiros viajados pelo texto dela, uma vez que foram compartilhados em perfis pessoais dos comentaristas do blog. A própria Adelina sinaliza, por meio de referência local (fiz questão que postá-lo no face), uma nova trajetória textual do artigo de opinião de Charô, ao compartilhá-lo em seu perfil no Facebook.

Outro exemplo de entextualização de concordância com o Discurso de Charô, na trajetória textual do elogio aqui em análise, está no comentário de Erika, que afirma já ter discutido com uma branca, sugerindo um termo pejorativo para esta participante sobre a questão do ser chamada de morena: 
Já cheguei a discutir com uma branca que insistia em afirmar: Erika você não é negra, não se diminua, você é morena! Se vc quer militar pois bem, mas assuma o que você é. Isso me marcou profundamente! Minha pesquisa é justamente em cima desses estereótipos que parecem elogio e figuram como preconceito. Amo tudo o que você escreve e identificação é máxima, obrigada Charô por expressar tão bem as angústias que nós mulheres negras vivenciamos. (Erika).

A mesma construção do termo negra como negativo, observada anteriormente, é mencionada por Erika ao usar a citação ("Erika você não é negra"). Tal construção é sinalizada pela predicação (não é negra) e pela negação (não se diminua), sugerindo que negras são consideradas sujeitos sociais ruins e abjetos; ademais, ao se autodeclarem como tal, estas negras estariam se inferiorizando. As referências negra e diminua são construídas aqui como parte do mesmo campo semântico. Identificamos ainda que a predicação (você é morena!) acompanhada pelo ponto de exclamação indica a tentativa de embranquecer a participante e também parte das mulheres negras. Verificamos que Erika faz uso da citação indexicalizando, assim, Discursos de outras/os e enfatizando a verosemelhança de seu relato como identificado no texto de Adelina.

A militância é outro aspecto relevante apontado no comentário citado. Ao entextualizar textos de outros em seu comentário, pela citação ("Se vc quer militar pois bem, mas assuma o que você é"), podemos dizer que para os interlocutores de Erika ser militante não requer que ela seja negra, visto que sê-lo é negativo. Já o assumir-se aqui está relacionado à materialidade do seu corpo que para tais interlocutores seria o assumir-se morena, embranquecendo-se e, portanto, valorizando-se.

Em seu comentário, essa participante cita ainda sua pesquisa sobre os estereótipos que figuram como preconceito, ratificando assim o Discurso de Charô de que a temática é importante para a comunidade negra. Este aspecto é sugerido pela referência (minha pesquisa, desses estereótipos, elogio, preconceito). Como em muitos comentários analisados, Erika elogia Charô e a parabeniza pelo texto; isto é indexicalizado pelas referências pronominais (amo tudo o que você escreve) e por meio de predicação(e identificação é máxima), sinalizando a identificação de Erika com a autora. Além disso, há também um agradecimento indicado pela predicação (obrigada), sugerindo a importância de dar voz às dores de muitas mulheres negras no coletivo, indicada pela referência e predicação (nós, mulheres negras). Ademais, pelas referência e predicação (expressar tão bem as angústias que nós mulheres negras vivenciamos), a participante indexicaliza a reflexividade típica de nossos tempos de Modernidade Recente, que traz à tona os significados cristalizados na Modernidade. 
A segunda ordem de indexicalidade, aceitação do elogio, identificada nos comentários viaja na contramão das críticas apresentadas por Charô em seu texto. Estela, por exemplo, traz à tona essa outra trajetória, indexicalizada por meio de predicação (sinceramente não me incomoda), que sinaliza não se importar com o elogio que a constrói como morena. A participante justifica o não incômodo pela assertiva explicativa ("...a maioria das pessoas (principalmente quem é branca) tem receio de falar negra"), sugerindo que compreende a preferência pelo termo morena, devido ao receio de brancos serem taxados de racistas por empregarem o item lexical negra. Tal receio de alguns sujeitos sociais não-negros está indexicalizado pelas referência pronominal e predicação ("... ela não tem intimidade ela se refere como "morena" mesmo. Ela mesma já me disse que tem medo de chamarem ela de racista"), indicando que a intimidade é um fator que levaria um sujeito social de outra raça a usar o termo negra ou morena:

Ser chamada de "morena" sinceramente não me incomoda, porque sei que a maioria das pessoas (principalmente quem é "branca") tem receio de falar "negra". Tenho uma amiga "branca" que me chama de "black" "preta" e até de "negona" mesmo, a intimidade gerou isso. Mas para falar de outra pessoa que ela não tem intimidade ela se refere como "morena" mesmo. Ela mesma já me disse que tem medo de chamarem ela de racista, mesmo ela namorando com um negro e tendo praticamente a família e os amigos de maioria negra. (Estela).

Operando dentro da mesma ordem de indexicalidade, há o depoimento de Eunice que ilustra a aceitação do elogio ou a dificuldade de se nomear negro de um aluno que era construído por sua família como moreninho. Essa aceitação é sugerida pela predicação (... ensinava que ele era "moreninho"), mostrando, desta forma, que a própria família do aluno negro evitava empregar o termo negro. Imbricada nesta aceitação do termo morena, observamos, no comentário de Eunice, também evidenciado por Estela, a caracterização do sujeito social como negro considerada negativa. Isto é indicado pelas referência e predicação (TODOS sem graça disseram que eu era branca), além da maiúscula sinalizando indignação, quando a professora relata que seus alunos também tinham receio de chamá-la de negra:

Sou professora, recente em uma aula sobre raças comuns no Brasil, sugeri que meus alunos (entre 6 e 7 anos de idade) falassem de suas raças, quando um deles ficou constrangido quando comentamos que ele era negro, quando questionada pela família dele percebi que o meu aluno sofria preconceito da própria família, que o ensinava que ele era "moreninho", nesse momento tive que ser firme com ele e sua família e expliquei que ser negro não é defeito, é apenas uma raça como as outras existentes em minha sala de aula, índios, brancos, mulatos e negros também. Ao perceber esses preconceitos "mascarados" em meus alunos os perguntei qual era a minha raça e eles ficaram com vergonha e receio de dizer que eu era negra ou mulata, TODOS sem graça disseram que eu era branca, lábios grandes, nariz arrendondado e cabelos encaracolados então tive que na prática ensinar a eles que ser negra não defeito e nem sinal de 
pessoas feias e todos ficaram surpresos quando ouviram da minha boca que sim, sou mistura da raça negra e branca, de tal forma sou mulata! Parabéns pelo texto ótimo! (Eunice).

Nos dois comentários (de Estela e de Eunice) é possível perceber que o elogio criticado por Charô foi entextualizado de forma positiva por Estela e pelo aluno de Eunice, como evidenciado pela ordem de indexicalidade mobilizada. Contudo, para Eunice tal comentário seria um elogio que fere por ser racista e mascarado, como indicam referência e predicação (esses preconceitos "mascarados"). As referências (vergonha, receio) e a predicação (surpresos) indexicalizam que o termo negro ainda é construído como ruim e ofensivo. Podemos dizer que tal construção tem percorrido o tempo e diversos espaços, visto que como mencionado por Munanga (1986), desde os tempos da chamada ciência da raça, negras/os são qualificados como ruins, inferiores etc.

A participante Eunice traz à tona a cristalização do problema racial no Brasil na infância. Tal sedimentação pode ser percebida pela referência (que meus alunos (entre 6 e 7 anos de idade)), sinalizando que crianças das séries iniciais já compreendem que é negativo qualificar colegas ou professoras/es por negra/o. Esta construção que se inicia na infância é indexicalizada pela predicação (branca, lábios grandes, nariz arrendondado e cabelos encaracolados), quando as crianças descrevem a professora.

Como observado até aqui, nesta trajetória textual, os comentários se situam nas duas ordens de indexicalidade citadas, sendo que a maioria deles indexicaliza o elogio como ofensa ou um tipo de racismo velado que há nele. Essas duas ordens são observadas também na trajetória textual do elogio no Pragmatismo Político, contudo, há predominância de uma terceira que veremos a seguir.

\section{TRAJETÓRIA TEXTUAL DE VOCÊ É UMA MORENA MUITO BONITA NO SITE PRAGMATISMO POLÍTICO}

A mesma ordem de indexicalidade de ratificação do Discurso de Charô sobre o elogio ser ofensa é encontrada no site Pragmatismo Político. A participante Juliana, por exemplo, por meio de verbo no pretérito perfeito (passei), sinaliza ter vivenciado, o mesmo que Erika e Adelina, ao ser chamada de morena. Juliana, pela predicação (negra) e ainda por meio do verbo no presente (insisto), enfatizando que se compreende negra e ainda indicando, pela predicação (moreno), que moreno não existiria: 
Eu já passei por isso muitas vezes. E quando alguém me chama de morena eu insisto em dizer que sou negra, e não existe moreno. Infelizmente o povo brasileiro é racista. As mulheres negras ainda são vistas como um brinquedo sexual ou um troféu de uma ascensão social. Triste realidade (Juliana).

Assim como as outras duas participantes do Blogueiras Negras, Juliana também compreende o elogio como ofensa e aborda a questão do racismo, indexicalizado pela referência (brasileiro) e pela predicação (é racista), sugerindo que o racismo existe no Brasil, contrariando, dessa forma, o Discurso do senso comum de democracia racial. Ela menciona, por meio de referência e predicação (mulheres negras), que todas as mulheres negras são objeto sexual, indicado pela referência e predicação (brinquedo sexual).

Outro exemplo desta perspectiva pode ser observado no comentário do participante Renato ao usar a referência e a predicação (esses elogios racistas), indicando que todos os elogios citados pela autora do texto são preconceituosos:

esses elogios racistas estaum taum encravados na nossa cultura e na nossa sociedade, q acabam passando despercebidos. axo louvável essas ponderações pq a hipocrisia impera quando se toca nesse assunto. existem preconceito no brasil, principalmente contra os negros q saum a maioria em nosso país (Renato)

Além disso, podemos observar que para o participante tais elogios são considerados naturalizados e sedimentados na sociedade. Tal aspecto é indexicalizado pela predicação (taum encravados) e pela assertiva (que acabam passando despercebidos), ambos sinalizando essa naturalização; pela referência de localidade (na nossa cultura e na nossa sociedade), Renato sugere uma construção cultural sobre raça que permeia toda a sociedade. Ele ratifica também a questão do preconceito pela referência (preconceito no Brasil) e especificamente contra um grupo, o que é indicado pela referência (os negros). Ele ainda comenta a relevância do texto de Charô, através da modalidade epistêmica (axo louvável essas ponderações), e aponta a hipocrisia da negação do preconceito pelo uso da assertiva (pq a hipocrisia impera quando se toca nesse assunto).

Na trajetória textual em análise, são precipitados Discursos sobre a escravidão chancelada pelo Discurso religioso. O post que inicia esta discussão específica também foi muito comentado por uma parte dos participantes. Esta perspectiva religiosa da raça é sugerida pela referência (deus, livro, obra), pela predicação (sagrado), que sinalizam a maldição de Cão ${ }^{9}$ presente no livro do Gênesis,

9 Para maiores informações, ver http://pt.wikipedia.org/wiki/G\%C3\%AAnesis. 
entextualizada ao longo da história para justificar a escravidão negra e citada pelo deputado/pastor Marcos Feliciano ${ }^{10}$ como noticiado na imprensa:

[...] deus não existe e não fez mulher nenhuma, o mesmo deus que você paga pau é o que diz que os negros são inferiores no seu livro sagrado preconceito é a única obra de deus... (Mauro).

Esta construção provoca questionamentos de alguns participantes, como por exemplo, o de Rodrigo que pelo uso de referência (bíblia, negro, gente, comentários, abobrinhas) e de predicação (inferior, estúpida, preconceituosas, mentirosas), sugere que esse Discurso religioso específico é uma inverdade:

Desde quando na Bíblia está que negro é inferior. Cada gente estúpida vejo nesses comentários; vão estudar antes de espalharem abobrinhas preconceituosas e mentirosas (Rodrigo).

Como no Blogueiras Negras, deparamo-nos também com a segunda ordem de indexicalidade, elogio/ofensa é aceitável, ou seja, com o receio em empregar o termo negro e a preferência pelo termo morena, como forma de não ofender os corpos ébanos. Essa dificuldade de se nomear negra, citada por Eunice do Blogueiras Negras, é movimentada também no comentário de Rafael, do Pragmatismo Político, quando ele aborda o fato de negras se autodenominarem morenas. Tal ponto é indexicalizado pela referência e pela predicação (mulher negra, morena) e pelo descritor metapragmático (dizendo): "Zorra, o quanto eu já vi de mulher negra se dizendo morena (Rafael)".

Kelven, operando na mesma ordem de indexicalidade de Estela, cita este aspecto ao usar a assertiva (muita gente diz morenx para se referir a uma pessoa negra, porque não querem ser ofensivos). Ele também aborda a questão racial vivenciada, no passado, em solo brasileiro pela referência (preconceitos)e pela predicação (raciais históricos). Ademais, ele complementa que o termo morenx já está normalizado ao empregar a referência (muitas pessoas), a predicação (morena, negra), pelos verbos (usam, cresceram, falando), que indexicalizam ações construídas desde a infância Identificamos, também, que o x ao final de morena apagaria as questões de gênero, indexicalizando, somente, o Discurso sobre raça:

(...) Muita gente diz usa morenx para se referir a uma pessoa negra porque não querem ser ofensivos, já que o termo remonta preconceitos raciais históricos. Mas muitas pessoas já usam simplesmente morena por negra porque cresceram falando assim. Eaí, racismo? Racismo é criar uma cartilha de como chamar as pessoas brancas e as pessoas negras. (Kelven).

10 Mais informações em http://noticias.uol.com.br/politica/ultimas-noticias/2011/03/31/deputadofederal-diz-no-twitter-que-africanos-descendem-de-ancestral-amaldicoado.htm. 
Observamos que ao mesmo tempo em que aborda o fato de os negros se autodeclararem morenos, o participante também cita brevemente a questão de se criar regras para nomear ou dirigir-se a brancos e negros. Tal ponto é indexicalizado pela indagação ("E aí, racismo?") e pela assertiva ("Racismo é criar uma cartilha de como chamar as pessoas brancas e as pessoas negras"), sinalizando que compartilha, também, dos comentários da terceira ordem de indexicalidade, elogio não é ofensa, que exploraremos a seguir.

Diferentemente do observado na trajetória textual do elogio em questão no Blogueiras Negras, aqui temos a discordância total dos argumentos propostos por Charô. Há um conjunto de comentários que não ratificam o elogio como ofensa. Identificamos várias indexicalizações que cristalizam tal sentido, como por exemplo, os posts de Kelven, Pedro, Wilson e Mauro, que sintetizam muitos dos comentários nessa ordem específica. Pedro sinaliza por meio de predicação (baixa, não são racistas) e de referência (autoestima, racismo, esses elogios, culpa, ambiente, brincadeira), que aquele que aborda o racismo é na verdade racista, ou seja, preconceito existe apenas para aquela pessoa:

\footnotetext{
Minha opinião é: Vc tem BAIXA AUTO ESTIMA e o racismo esta DENTRO de vc. Sinceramente, esses elogios que vc postou não são racistas, sua mente está perturbada, não que isso seja culpa sua, com certeza o ambiente que vc viveu deve ter te condicionado a isso. Sem brincadeiras, procure ajuda. (Pedro).
}

Ademais, o participante indexicaliza Discursos da Psicologia para compreender o motivo da autora ter publicado tal texto por meio de um campo semântico relacionado a distúrbios psicológicos (mente, perturbada, procure ajuda, ambiente que você viveu). Percebemos ainda que o uso de letras maiúsculas (DENTRO; BAIXA AUTO ESTIMA) sugerem gritos nas redes sociais que podem sinalizar aqui o quão sedimentado e incômodo é abordar a temática discutida no artigo de Charô, além de ressaltar a, agressividade de Pedro.

Ainda sobre a patologização, ela é indexicalizada, no post de José Carlos, pela referência (esquizofrenia, cabeça, preconceito), pela modalidade epistêmica (acha) e pelo verbo no presente (existe), sinalizando sua opinião a respeito da inexistência de ofensa pelo elogio, consequentemente a ausência do preconceito, e enfatizando um dos Discursos que permeia a sociedade brasileira: o racista e o problemático é aquele que aborda o tema racial, assim, como Pedro e Kelven: "O Mauro está certo. O preconceito só existe na cabeça de quem acha que sofre. É quase uma esquizofrenia... (José Carlos)".

$\mathrm{Na}$ mesma perspectiva agressiva de Pedro, identificamos também o comentário de Mauro que discorda da maior parte do texto. Tal aspecto é sugerido 
pelo uso da modalidade epistêmica(não concordo, acho), pela referência (maioria do texto) e pela predicação (frescura):

não concordo com a maioria do texto, acho muita frescura, não pode chamar negro de moreno, e não pode chamar de negro tbm, não pode chamar de nada, tudo eh preconceito, ora o negro não eh negro? qual o problema de dizer que ele eh negro, isso sim q eh preconceito. Pra mim o preconceito deixa de existir quando nós pararmos de pensar nele, e esse texticulo faz um papel contrário ao que se propõe a traz a tona pensamentos preconceituosos da própria autora. (Mauro).

A agressividade aqui é sinalizada pela referência (texticulo), em que autor troca s pelo $\mathrm{x}$ diminuindo, assim, o artigo da autora, ao passo que tal referência também indexicaliza Discursos machistas ao se referir à parte da anatomia masculina em um jogo de duplo sentido. Ademais, o participante também sugere que racista é aquele que aborda o preconceito ao utilizar a referência (pensamentos, autora) e a predicação (preconceituosos), e aponta, por meio da assertiva (o preconceito deixa de existir quando nós pararmos de pensar nele), que todos os atores sociais deveriam adotar o silêncio sobre a temática, já que ele apagaria a questão e resolveria o problema do preconceito racial em contexto brasileiro.

Outro exemplo de negação do elogio como ofensa está no post de Vinicius que indexicaliza a não ofensa ao fazer uso de referência (conversa, país, racismo, tipo de fobia, cabeça, pessoa) e de predicação (triste), sinalizando, como os outros participantes do site Pragmatismo Político, que o racista é aquele que aborda o racismo:

Eu acho sinceramente triste, termos este tipo de conversa num país como o nosso. Acho que o racismo, e qualquer outro tipo de fobia está na cabeça da pessoa. [...] Sou o típico brasileiro, cheio de misturas, e não julgo ninguém pela cor de sua pele, caráter, respeito não tem cor (Vinícius).

Vinicius ainda trata da questão da miscigenação, um dos Discursos que constituem a democracia racial, e que indexicaliza que o racismo é inexistente e o elogio inofensivo. Tal aspecto é indicado pela referência (cor da pele, caráter, respeito, cor) e pela predicação (típico brasileiro, cheio de misturas), que também mostram a sedimentação dos Discursos sobre democracia racial.

Como observado, nesta trajetória, deparamo-nos com três ordens de indexicalidade distintas. De um lado, a primeira e a segunda (elogio como ofensa e aceitação do elogio) são entextualizados de forma semelhante nos comentários tanto no Blogueiras Negras como no Pragmatismo Político, mostrando-nos uma convergência entre os dois espaços e percursos. Por outro lado, no site do Pragmatismo Político, percebemos que são inaugurados sentidos cristalizados de 
que o ato performativo Você é uma morena linda não seria ofensivo, pelo contrário, o problema estaria na autora que, segundo os resultados desse percurso, seria racista, mal resolvida com sua raça e sofredora de alguma patologia. Observamos, então, nas três ordens de indexicalidade, que são precipitados Discursos da democracia racial, miscigenação e racismo, que têm persistido em muitos textos ao longo do tempo.

\section{CONSIDERAÇÕES FINAIS}

As duas trajetórias analisadas, no Blogueiras Negras e no Pragmatismo Político, e também as três ordens de indexicalidade mobilizadas nos dois espaços, sinalizam a importância de desnormalizar ou queerizar os elogios/ofensas que escondem ou escamoteiam preconceitos e racismo. Além disso, observamos que sentidos e efeitos semânticos racistas estão sendo construídos por meio dos ingênuos elogios que circulam na sociedade. Com base em Butler (1997), podemos dizer que desde cedo crianças já estão fazendo coisas com a linguagem e neste caso construindo sedimentações sobre o que é ser negra, morena e também branca. Ainda conforme a autora, é possível afirmar que somos compreendidos distintivamente segundo a legitimidade de determinada raça. Nos dados aqui analisados, vimos que uma professora negra foi legitimada como branca por seus alunos para evitar ofensa.

Segundo Munanga (2004), no Brasil, quando se está diante de negras/os, observa-se uma dificuldade em assim denominá-los/as. Desse modo, opta-se por chamar esse sujeito social de moreno/a, como uma tentativa de embranquecê-lo e/ ou de não ofendê-lo. De acordo com o autor, os brasileiros teriam sido construídos para encenarem tais performances identitárias diferentemente dos estadunidenses, por exemplo, que são construídos para assumir suas práticas racistas. Nesta pesquisa, podemos notar que, apesar da trajetória de diversos textos sobre a questão racial ao longo dos séculos, ainda hoje nos deparamos com a precipitação em Discursos locais de sedimentações sobre, por exemplo, ser negra e morena, em que o primeiro é construído como ruim. Embasados em Butler (2004), podemos dizer que as predicações negra e morena mobilizam Discursos referentes ao reconhecimento da morfologia de raça.

Nas práticas sociais, elogiar mulheres negras como morenas, ou na perspectiva de Muñoz (1999), identificá-las como morenas, moreninhas ou morenas escuras, escamoteia a dificuldade de olhar ou abordar a questão racial em contexto brasileiro. Além disso, ao proferir tais atos de fala performativos ou elogios, a materialidade negra que constitui essas mulheres seria apagada ou embranquecida para que elas 
sejam aceitas. Neste sentido, tais atos mascarados de elogios encobertam um racismo e/ou as identificam a valores que as tornam aceitáveis para uma parte da sociedade. Percebemos, assim, a necessidade teórica de compreender o sujeito social sempre interseccionado por raça, gênero, sexualidade etc. como traços performativos imbricados, que o constroem, no caso desta investigação, como mulheres negras. A questão racial é tão cristalizada e naturalizada, como nossa análise indica, que incita a imprescindibilidade de nas práticas institucionais (escolas, universidades etc.) entendermos a importância de desidentificar, reinventar e desconstruir tais construções binárias de negra e morena, o que pode ensejar menos sofrimento aos corpos negros, considerados ainda abjetos na sociedade brasileira.

Esta investigação, além de contribuir para o desenvolvimento de estudos sobre linguagem e raça, nos mostra a necessidade de estudar práticas online, já que nas viagens textuais online é possível que novas ordens de indexicalidade possam ser construídas, tendo em vista o alto nível de reflexividade sobre a vida social em desenvolvimento em tal contexto. No entanto, nossa análise, ao levantar as três ordens de indexicalidade precipitadas nas duas trajetórias textuais traz à tona os mesmos significados tensionados na sociedade brasileira sobre a questão racial, anteriormente discutidos, ou seja, Discursos de democracia racial (cf. SODRÉ, 1999), de miscigenação (cf. MUNANGA, 2004) e de racismo - aqui velado (cf. TELLES, 2003).

\section{REFERÊNCIAS BIBLIOGRÁFICAS}

AUSTIN, J. L. (1962/1990). Quando dizer é fazer. Palavras e ação. Trad. Danilo Marcondes. Porto Alegre: Artes Médicas.

BARNARD, I. (2004). Queer race: cultural interventions in the racial politics of queer theory. New York: Peter Lang.

BAUMAN, Z. (2008). Vida para consumo. Trad. Carlos Alberto Medeiros. Rio de Janeiro: Jorge Zahar.

BAUMAN, R.; BRIGGS, C. (1990). Poetics and performance as critical perspectives onlanguageand social life. In: American Review of Anthropology, v. 19, p. 59-88.

BAUMAN, R.; BRIGGS, C. (2003). Voices of modernity: language ideologies and the politics of inequality. Cambridge: Cambridge University Press.

BLOMMAERT, J. (2006). Social linguistics scales. London: Working Papers Urban Language \& Literacies. London: King's College.

BLOMMAERT, J. (2010). The sociolinguistics of Globalization. Cambridge: Cambridge University Press. 
BLOMMAERT, J; DONG, J. (2006). Etnographic fieldwolk: a beginner's guide. Bristol: Short Run Press.

BLOMMAERT, J; DONG, J. (2008). Language and movement in space. In: AURER, P. Handbook of Language and Space. Berlin: Mouton de Gruyter.

BUTLER, J. (1997). Excitable speech: a politics of the performative. New York: Routledge.

BUTLER, J. ([1998] 2002).Fundamentos contingentes: o feminismo e a questão do pós-modernismo. Cadernos Pagu, Campinas, v. 11, p.11-42.

BUTLER, J. ([1999]2003). Problemas de gênero: feminismo e subversão da identidade. Trad. Renato Aguiar. Rio de Janeiro: Civilização Brasileira.

BUTLER, J. (2004). Performative acts and gender constitution: an essay in phenomenology and feminist theory. In: BIAL, H. (Org). New York: The performance studies reader.

COSTA DE PAULA, R. (2003). Construindo consciência das masculinidades negras em contexto de letramento escolar: uma pesquisa-ação. In: MOITA LOPES, L. P. (Org.). Discursos de identidades. Campinas: Mercado de Letras, p. 181-208.

COSTA DE PAULA, R. (2010). "Não quero ser branca não. Só quero um cabelo bom, cabelo bonito" Performances de corpos/cabelos de adolescentes negras em práticas informais. Tese (Doutorado em Linguística Aplicada). Instituto de Estudos da Linguagem, Universidade Estadual de Campinas, Campinas.

DERRIDA, J. [1972] 1988]. Signature event context. Limited inc. Evanston: Northwestern University Press. p. 1-23.

FABRÍCIO, B.F. (2013). A "outridade lusófona" em tempos de globalização: identidade cultural como potencial semiótico. In: MOITA LOPES, L.P.(Org.). O português no século XXI: cenário geopolítico e sociolinguístico. São Paulo: Parábola, p. 144-168.

FERREIRA, A. J. (2006). Formação de professores raça/etnia: reflexões e sugestões de materiais de ensino. Cascavel: Coluna do Saber.

FERREIRA, A. J. (2009). Formação de professores de linguas: bistórias de professoras negras e brancas de inglês e suas experiências com o racismo. In: FERREIRA, A. J. Formação de Professores de Línguas: investigações e intervenções. Cascavel: Edunioeste, p.67-84.

FOUCAULT, M. (2010). Os Anormais. São Paulo: Martins Fontes.

GEE, J. (2004).Situated Language and Learning. A critique of traditional schooling. New York: Routledge.

GIACOMINI, S.M. (2013). Mulber e Escrava: uma introdução ao estudo da mulher negra no Brasil. 2. ed. Curitiba: Appris.

GOMES, N. (2010). Intelectuais negros e produção do conbecimento: algumas reflexões sobre a realidade brasileira. In: SANTOS, B.S.; MENESES, M.P. (Orgs)Epistemologias do Sul. São Paulo: Cortez, p. 492-516.

GUIMARÃES Jr., M.J.L. (2005). Doing antbropology in cyberspace: fieldwork boundaries and social environment. In: HINE, C. Virtual methods: issues in social research on the internet. Oxford: Berg Publishers, p.157-170. 
HEILBORN, M. L.(2006). Entre as Tramas da Sexualidade Brasileira. Estudos Feministas, Florianopólis, v. 14, n. 1, p. 43-59.

HINE, C. (2000). Virtual Ethnograpby. London: Sage Publications.

HINE, C. (2005).Virtual Methods: issues in social research on the internet. Oxford: Berg Publishers.

MACIEL, M.E.S. (1999). A engenia no Brasil. Anos 90, Porto Alegre, n. 11.

MARYNS. K; BLOMMAERT, J. (2013). Conducting dissonance: code switching and differential access to context in the Belgian. Disponível em < http://www.lang.soton.ac.uk/lipp/restricted/ LIPP_MarynsBlommaert.pdf>. Acesso em: 9 dez. 2013.

MELO, G.C.V.; MOITALOPES, L.P. (2013). As performances discursivo-identitárias de mulheres negras em uma comunidade para negros na Orkut. Delta, PUC, São Paulo, v. 29, p. 237-265.

MELO, G.C.V.; MOITALOPES, L.P. (2014a). A performance narrativa de uma blogueira: "tornando-se preta em um segundo nascimento". Alfa Revista Linguística, Unesp, Araraquara, v.58, p. 541-56.

MELO, G.C.V.; MOITALOPES, L.P. (2014b).Ordens de indexicalidade mobilizadas nas performances discursivas de um garoto de programa: ser negro e homoerótico. Lingua(gem) em Discurso, v.14, n 3. p. 653-673.

MOITA LOPES, L.P.(2002).Identidades fragmentadas: a construção discursiva de raça, gênero e sexualidade em sala de aula. Campinas: Mercado de Letras.

MOITA LOPES, L.P. (2005). A construção do gênero e do letramento na escola: como um tipo de conhecimento gera outro. Investigações (Recife), Recife (UFPE), v. 17, n.2, p. 47-68.

MOITA LOPES, L.P. (2013). Gênero, sexualidade, raça em contextos de letramentos escolares. In: MOITA LOPES, L. P. (Org.) Linguística Aplicada na Modernidade Recente. São Paulo: Parábola, p.227-247.

MUNANGA, K. (1986). Negritude Usos e Sentidos. São Paulo: Ática.

MUNANGA, K. (2004). A difícil tarefa de definir quem é negro no Brasil. Estudos Avançados, São Paulo, v. 18, n.50.

MUNANGA, K. (2010). Mestiçagem como símbolo da identidade brasileira. In: SANTOS, B.S.; MENESES, M.P.(Orgs.) Epistemologias do Sul. São Paulo: Cortez, p. 443-492.

MUÑNZ, J.E. (1999). Disidentifications. Queers of Color and the performance of politics. Minneapolis: University of Minnesota Press.

OCHS, E. (1992). Indexing gender in retbinking context: language as an interactive phenomenon, A. Duranti; C. Goodwin. (Orgs.) Cambridge: Cambridge University Press, p.335-358.

PENNYCOOK, A. (2007). Performance and performativity. In: PENNYCOOK, A. Global Englishes and transcultural flows. New York: Routledge.

PINTO, J. P. (2007). Conexões teóricas entre performatividade, corpo e identidade. Delta, v. 27, n. 1, p. $1-16$.

PRINS, B.; MEIJER, I. (2002). Como os corpos se tornam matéria: entrevista com Judith Butler. Estudos Feministas, v. 1, p. 155-167. 
RAMPTON, B. (2006). Late modern language, interaction and schooling. In: RAMPTON, B. Language in Late Modernity: interaction in an urban school. Cambridge: Cambridge Press.

ROCHA, L. L. (2013) Teoria queer e a sala de aula de inglês na escola pública: performatividade, indexicalidade e estilização. Tese (Doutorado). Rio de Janeiro: Universidade Federal do Rio de Janeiro, Faculdade de Letras.

RUTTER, J.; SMITH, G. (2005). Ethnografic presence in nebulous settings: a case study. In: HINE, C. Virtual Methods: Issues in Social Research on the Internet. Oxford: Berg Publishers, p. 81-92.

SANTOS, B. de S. (2004). Do pós-moderno ao pós-colonial e para além de um e outro. Coimbra: Conferência de abertura ao VIII Congresso Luso-Afro-Brasileiro de Ciências Sociais.

SANTOS, M. Por uma outra globalização. Rio de Janeiro: Hucitec, 2000.

SEDGWICK, E. K.([1990] 2008). Epistemology of the Closet. London: Penguin.

SILVERSTEIN, M. (2003). Indexical order and the dialectics of sociolinguistic life. Language \& Communication, v. 23, p. 193-229.

SODRÉ, M. (1999). Claros e Escuros. Rio de Janeiro: Vozes.

SOMMERVILLE, S. B. (2000). Queering the color line. Race and the inventions of bomosexuality in American culture. Durham: Duke University.

SULLIVAN, N. (2003). A critical introduction to queer theory. New York: New York University Press.

TELLES, E. (2003). Racismo à brasileira: uma nova perspectiva sociológica. Rio de Janeiro: RelumeDumará.

VENN, C. (2000). Occidentalism, modernity and subjectivity. London: Sage Publications.

WORTHAM, S. (2001). Narratives in action. New York: Teacher College Press.

Recebido: 30/01/2014

Aceito: 1/03/2015 